\title{
ANALISIS KONVERSI LAHAN SAWAH DI KOTA SOLOK
}

\section{Mardianto 1}

Email Author: mardianto.anto69@gmail.com

\begin{abstract}
Agricultural land conversion occurs mostly in big cities in Indonesia and also occurs in small villages and towns on a small scale but not much has been done by the study. This study was linked to detect factors affecting land conversion in Kota Solok. This research was conducted by survey method. Sampling is done by simple random sampling with balanced amount. The data collected in this study includes primary data and secondary data. The analysis is done by description using percentage of respondent's level of achievement (tcr). The result of the analysis shows that the conversion of paddy fields in Solok City is mostly done by individual buyers, the internal factor which has the greatest effect on the conversion of paddy fields in Solok City is the economic condition, while the external factor is caused by the population growth and the policy caused by the weakness of policy control which government apparatus.
\end{abstract}

Keywords: Conversion, paddy fields

\section{PENDAHULUAN}

Selama ini Indonesia dikenal luas sebagai negara agraris yang bertumpu pada pertanian sebagai penyumbang devisa terbesar. Disisi lain penduduk Indonesia bertambah sedemikian cepat dan mengakibatkan kebutuhan akan lahan juga meningkat, sehingga konversi lahan pertanian, khususnya lahan sawah sulit untuk dihindari. Hal ini disebabkan oleh alasan ekonomi dimana setiap orang ingin memperbaiki taraf hidupnya dan mempunyai akses yang mudah terhadap sumber daya yang ada di sekitar mereka, untuk itu lahan yang mereka miliki yang biasanya diusahakan pertanian dikonversikan penggunaannya ke non pertanian.

Konversi lahan pertanian tidak bisa dilepaskan dari proses transfer pemilikan lahan, khususnya proses jual beli tanah, karena harga akan tinggi karena berdekatan dengan pusat perkembangan pembangunan (Rustiadi dan Wafda, 2005). Selain itu ada juga petani/pemilik yang menjual lahannya disebabkan oleh kebutuhan rumah tangga yang mendesak, seperti membayar hutang, membiayai pendidikan anak, dan keperluan lainnya.

Konversi lahan pertanian selain terjadi di kota-kota besar di Indonesia, juga terjadi di desa dan kota-kota kecil dalam skala kecil oleh para pemilik lahan. Mereka mengkonversi lahan pertaniannya menjadi bentuk non pertanian, seperti halnya di Kota Solok Provinsi Sumatera Barat yang memiliki luas 57,64 kilometer persegi dengan jumlah penduduk 60.530 jiwa pada tahun 2009 (BPS Kota Solok, 2010) dan laju pertumbuhan penduduk sebesar 1,24 $\%$ dan menempati uratan ke 4 (empat) dari kabupaten/kota yang ada di Sumatera Barat.

Selama 20 tahun terakhir (tahun 1994-2013) di Kota Solok telah terjadi konversi lahan sawah menjadi lahan non

\footnotetext{
${ }^{1}$ Staff Pengajar Program Studi Agribisnis Fakultas Pertanian Universitas Mahaputra Muhammad Yamin Solok
} 
pertanian yang cukup tinggi, yaitu sekitar 428,4 ha (Dinas Pertanian Kota Solok, 2014). Penurunan luas lahan sawah (konversi/pengalihan penggunaan ke bentuk lain) terjadi pada semua jenis lahan sawah, namun yang terluas terjadi pada sawah dengan irigasi $1 / 2$ teknis.

Konversi lahan yang dilakukan oleh petani dalam skala kecil ini belum terlalu banyak diteliti, maka penelitian ini difokuskan pada fenomena tersebut. Berdasarkan alasan-alasan ini perlu dilakukan sebuah penelitian untuk menganalisis konversi lahan sawah ke bentuk penggunaan lain di Kota Solok guna menemukan faktor-faktor yang mempengaruhi konversi lahan sawah di Kota solok.

Hasil penelitian ini diharapkan dapat memberikan kerangka teoritikal analisis faktor yang dominan mempengaruhi konversi lahan pertanian khususnya konversi lahan sawah dan diharapkan dapat menjadi pedoman dan pertimbangan bagi masyarakat dalam melakukan konversi lahan pertanian, selain itu juga dapat dijadikan sebagai masukan dan pertimbangan dalam melahirkan kebijakan terutama berkaitan dengan pengendalian konversi lahan pertanian.

\section{METODOLOGI PENELITIAN}

Penelitian ini akan dilaksanakan di Kota Solok Provinsi Sumatera Barat dengan metode survey. Pendekatan yang digunakan adalah deskriptif kuantitatif. Pengambilan sampel dilakukan secara simple random sampling. Sampel 4. diambil sebanyak 30 orang dengan jumlah yang seimbang (proportionat) pada setiap kelurahan yang memiliki lahan sawah dan telah dikonversikan menjadi lahan non sawah di Kota Solok.

Data yang digunakan dalam penelitian ini meliputi data primer dan data sekunder. Variable dalam penelitian meliputi konversi lahan sawah, faktor internal, faktor eksternal dan faktor kebijakan pemerintah Data yang diperoleh dalam bentuk kualitatif selanjutnya dikuantitatifkan dengan menggunakan skala likert dengan tiga kriteria. Bila pernyataan positif maka nilai jawaban adalah $(3=$ setuju, $2=$ kurang setuju dan $1=$ tidak setuju), dan sebaliknya bila pernyataan negatif maka nilai jawaban adalah $(1=$ setuju, $2=$ kurang setuju dan 3 = tidak setuju). (Rianse dan Abdi, 2009). Selanjutnya data dianalisis dengan menghitung tingkat capaian dari masing-masing jawaban responden setiap variable secara persentase. Dengan rumus:

$\mathrm{TCR}=\frac{R_{s}}{\mathrm{n}} \times 100$

Dimana:

$\mathrm{TCR}=$ Tingkat capaian jawab responden (\%)

$\mathrm{R}_{\mathrm{S}}=$ Rata-rata skor jawaban responden $\mathrm{n}=$ Nilai skor jawaban

Nilai persentase dimasukkan ke dalam kriteria sebagai berikut:

1. 76-100\% kategori jawabannya tinggi

2. 56-75\% kategori jawabannya sedang

3. $<56 \%$ kategori jawabannya rendah 


\section{PEMBAHASAN}

Tabel 1 Skor capaian variabel konversi lahan sawah

\begin{tabular}{llcccc}
\hline No. & Indikator & Skor Total & Rata-Rata & $\%$ & Ket. \\
\hline 1 & Dilakukan Sendiri & 230 & 1.92 & 63.89 & sedang \\
\hline 2 & Dilakukan pembeli perorangan & 126 & 2.10 & 70.00 & sedang \\
\hline 3 & Dilakukan Pengembang & 117 & 1.95 & 65.00 & sedang \\
\hline 4 & Dilakukan Pemerintah & 210 & 1.75 & 58.33 & sedang \\
\hline Rata-rata & & 1.93 & 64.31 & sedang \\
\hline
\end{tabular}

Deskripsi pencapaian skor responden untuk variabel konversi lahan sawah adalah $64,31 \%$, dengan skor ratarata adalah sebesar 1,93 yang berada pada kategori sedang. Hal ini mencerminkan bahwa konversi lahan sawah yang dilakukan di Kota Solok baik oleh pemilik sendiri, swasta/pengembang maupun pemerintah berada pada kategori sedang. Memperhatikan masing-masing indikator konversi lahan sawah dapat dikatakan bahwa konversi lahan sawah lebih banyak dilakukan oleh pemilik perorangan, selanjutnya diikuti oleh pemilik. Konversi lahan sawah yang dilakukan oleh pengembang/swasta menempati urutan ketiga, sedangkan pemerintah mengkonveri lahan sawah dalam jumlah yang lebih kecil.

Hasil penelitian ini sejalan dengan penelitian yang dilakukan Astuti, Wibawa dan Ishak (2011) yang mengemukakan bahwa konversi lahan tanaman pangan ke penggunaan lain lebih banyak $(58,4 \%)$ disebabkan oleh faktor internal (ekonomi) pemilik lahan dan sisanya $(41,6 \%)$ disebabkan oleh faktor ekternal (lingkungan dan teknis). Dalam penelitian lain Iqbal dan Sumaryanto (2007) mengatakan bahwa kebijakan yang dikeluarkan pemerintah dan pemerintahan daerah berkaitan dengan penataan ruang wilayah juga berdampak tehadap terjadinya konversi lahan sawah.

Tabel 2 Skor capaian variabel faktor internal

\begin{tabular}{llcccc}
\hline No. & \multicolumn{1}{c}{ Indikator } & Skor Total & Rata-Rata & $\%$ & Ket. \\
\hline 1 & Kehidupan social & 172 & 1.91 & 63.70 & sedang \\
\hline 2 & Kondisi ekonomi & 309 & 2.06 & 68.67 & sedang \\
\hline 3 & Waris & 51 & 1.70 & 56.67 & sedang \\
\hline 4 & Hubungan dg lahan & 117 & 1.95 & 65.00 & sedang \\
\hline Rata-rata & & 1.91 & 63.51 & sedang \\
\hline
\end{tabular}

Deskripsi pencapaian skor responden untuk faktor internal adalah $63,51 \%$, dengan rata-rata adalah sebesar 1,91 yang berada pada kriteria sedang. Hal ini mencerminkan bahwa faktor internal petani dalam mengkonversi lahan sawah berada dalam keadaan sedang. Kondisi ekonomi petani merupakan indikator dari faktor internal petani yang paling besar mempengaruhi petani melakukan konversi lahan sawahnya. Hubungan petani dengan lahan menempati urutan kedua dari faktor internal yang menyebabkan petani 
mengkonversi lahan sawahnya. Indikator kehidupan sosial petani menempati urutan ketiga dari faktor internal yang menyebabkan petani mengkonversi lahan sawahnya, sedangkan sistem kekeluargaan/waris menempati urutan terakhir yang menyebabkan petani mengkonversi lahan sawah yang dimiliki.

Berdasarkan kondisi tersebut dapat dikatakan bahwa meningkatnya konversi lahan sawah ke bentuk penggunaan lain merupakan sebagai akibat peningkatan kebutuhan faktor internal petani (kehidupan sosial dan kondisi ekonomi, sistem kekeluargaan/waris serta hubungan dengan lahan sawah). Faktor sosial ekonomi yang menyebabkan masyarakat melakukan konversi lahan sawah, diantaranya adalah desakan ekonomi untuk pemenuhan kebutuhan hidup, kebutuhan tempat pemukiman dan tempat usaha lainnya, sulitnya pengairan karena berada di antara bangunan, tidak memiliki waktu yang cukup untuk mengusahakan lahan sawah karena adanya pekerjaan lain yang lebih menguntungkan dari berusahatani padi sawah, serta tingginya permintaan masyarakat yang berakibat tinggi harga tanah. Hal tersebut sejalan dengan Kaeksi dan Anna (2007) menyebutkan bahwa terjadinya konversi lahan pertanian sebagai akibat adanya pergeseran mata pencaharian masyarakat dari sektor pertanian ke non pertanian.

Sistem kekeluargaan/waris merupakan salah satu penyebabkan masyarakat melakukan konversi lahan sawahnya, diataranya adalah sebagai akibat sistem keturunan sehingga mereka membagi lahan kepada anak/kemenakan, selain itu juga disebabkan kepunahan (tidak memiliki keturunan) sehingga mereka cenderung menjual harta pusakanya (sawah). Bila lahan yang dikuasai merupakan lahan milik sendiri, maka petani akan dengan mudahnya melakukan konversi yang diawali dengan pemecahan lahan. Yuhri (2011) menyebutkan bahwa alih konversi lahan sawah marak terjadi karena hubungan kepemilikan yang cenderung berakibat terhadap fragmentasi lahan serta harga jual padi ditingkat petani yang rendah sehingga tidak seimbang dengan biaya produksi.

Tabel 3 Skor capaian variabel faktor eksternal

\begin{tabular}{llcccc}
\hline No. & Indikator & Skor Total & Rata-Rata & TCR & Ket. \\
\hline 1 & Pertumbuhan Penduduk & 66 & 2.20 & 73.33 & sedang \\
\hline 2 & Kelembagaan pemerintah & 125 & 2.08 & 69.44 & sedang \\
\hline 3 & Kelembagaan Masy & 129 & 2.15 & 71.67 & sedang \\
\hline Rata-rata & & & 2.14 & Sedang \\
\hline
\end{tabular}

Deskripsi pencapaian skor responden untuk faktor eksternal adalah $71,48 \%$, dengan rata-rata adalah sebesar 2,14 yang berada pada kriteria sedang. Hal ini mencerminkan bahwa faktor eksternal petani dalam mengkonversi lahan sawah berada dalam keadaan sedang. Pertumbuhan penduduk merupakan indikator dari faktor eksternal petani yang paling besar mempengaruhi petani mengkonversi lahan sawahnya. Kelembagaan masyarakat menempati urutan kedua dari faktor eksternal yang menyebabkan petani mengkonversi lahan sawahnya, sedangkan indikator kelembagaan pemerintah menempati urutan ketiga dari faktor eksternal yang menyebabkan petani mengkonversi lahan sawahnya. 
Simatupang dan Irawan (2009), Sihaloho, Darmawan dan Hadi (2007) serta Kaeksi dan Anna (2007) menyebutkan bahwa pertumbuhan penduduk mendorong terjadinya konversi lahan pertanian (sawah, tegalan, hutan/perkebunan) menjadi lahan terbangun (permukiman, gedung dan sarana umum). Selain itu kelembagaan masyarakat juga mendorong terjadinya konversi lahan sawah hal ini di buktikan adanya pihak swasta (pengembang) yang menawarkan dengan harga lebih atau menjanjikan masyarakat dengan pekerjaan sehingga mereka mau menjual tanah (sawah) yang selanjutnya terjadi perubahan pemanfaatannya. Nasution dan Winoto dalam Iqbal (2007) menyebutkan bahwa kelembagaan yang berkembang ditengah masyarat merupakan salah satu penyebab terjadinya konversi lahan pertanian.

Tabel 4 Skor capaian variabel kebijakan pemerintah

\begin{tabular}{llcccc}
\hline No. & Indikator & Skor Total & Rata-Rata & TCR & Ket. \\
\hline 1 & Kebijakan & 143 & 2.38 & 79.44 & Tinggi \\
\hline 2 & Pelaksanaan & 136 & 2.27 & 75.56 & sedang \\
\hline 3 & Pengawasan & 220 & 2.44 & 81.48 & tinggi \\
\hline Rata-rata & & 2.36 & 78.83 & Tinggi \\
\hline
\end{tabular}

Deskripsi pencapaian skor responden untuk variabel kebijakan adalah $78,83 \%$, dengan rata-rata adalah sebesar 2,36 yang berada pada kriteria tinggi. Hal ini mencerminkan bahwa variabel kebijakan berada dalam keadaan tinggi yang dapat menyebabkan petani mengkonversi lahan sawah. Indikator dari dari variabel kebijakan yang paling besar pengaruhnya terhadap konversi lahan sawah adalah pengawasan. Indikator kebijakan itu sendiri menempati urutan kedua dari variabel kebijakan yang menyebabkan konversi lahan sawahnya, sedangkan indikator pelaksanaan kebijakan menempati urutan ketiga dari variabel kebijakan yang menyebabkan konversi lahan sawahnya.

Isa (2005) menyebutkan bahwa secara Nasional sebenarnya sudah cukup banyak kebijakan yang mencegah konversi lahan pertanian, namun yang terpenting adalah bagai mana mengintegrasikan kebijakan pencegahan tersebut dengan pengaturan tata ruang wilayah. Konversi lahan sawah terus berkembang seperti tanpa kendali (Irawan et $a$. dalam Ilham, saukat dan Friyatno, 2005), untuk itu agar konversi lahan sawah produktif tidak terus terjadi, maka peraturan yang ada perlu diefektifkan dan dilengkapi dengan sistem pemberian sanksi bagi pelanggar dan sistem penghargaan atau insentif bagi yang patuh. Dengan demikian kebijakan pelarangan konversi lahan sawah akan efektif keberadaannya bila dilaksanakan dengan baik oleh pemerintah dan masyarakat, serta pelaksanaanya juga harus dibarengi dengan pengawasan yang ketat melalui pemberian sanksi bagi yang melanggar dan pemberian insentif bagi yang mematuhi.

\section{KESIMPULAN}

Secara umum dapat dikatakan bahwa konversi lahan sawah di Kota Solok lebih banyak dilakukan oleh pembeli perorangan, faktor internal yang paling besar pengaruhnya terhadap konversi lahan sawah di Kota Solok adalah kondisi ekonomi, sedangkan 
faktor ekternal disebabkan oleh pertumbuhan penduduk dan kebijakan disebabkan oleh lemahnya pengawasan kebijakan yang oleh aparatur pemerintah.

\section{SARAN}

Seiring dengan pertumbuhan penduduk maka peningkatan kebutuhan pangan beras tidak dapat dihindarkan, untuk itu diperlukan upaya peningkatkan produksi padi, salah satunya dengan menekan laju konversi lahan sawah melalaui program peningkatan kesejahteraan petani sehingga kesulitan ekonomi tidak dijadikan alasan mengkonversi dan menjual lahan sawah, selain itu pertumbuhan penduduk juga perlu ditekan. Berkaitan dengan kebijakan/peraturan, yang terpenting adalah mengefektifkan pelaksanaan kebijakan yang bersifat pengaturan yang diikuti dengan pengawasan yang ketat.

\section{DAFTAR PUSAKA}

BPS Kota Solok 2010. Kota Solok Dalam Angka.

Dinas Pertanian, Perikanan dan Kehutanan Kota Solok. 2014. Data Base Potensi Pertanian Kota Solok. Kerjasama Dinas Pertanian, Perikanan dan Kehutanan Kota Solok dengan Balai Pengkajian Teknologi Pertanian Sumatera barat.

Ilham, N., Y. Saukat dan S. Friyatno., 2005. Perkembangan dan FaktorFaktor yang Mempengaruhi Konversi Lahan Sawah serta Dampak Ekonominya. ojs.unud.ac.id.

Irawan, B. 2005. Konversi Lahan sawah : Potensi dampak, Pola Pemanfaatannya dan Faktor Determinan. Forum Penelitian
Agro Ekonomi. Volume 23 No. 1, Juli 2005: 1 - 18.

Isa, I. 2005. Strategi Pengendalian Konversi Lahan Pertanian. Badan Pertanahan Nasional.

Kaeksi, R.W dan Anna, A. N. 2007. Pertumbuhan Penduduk, Konversi Lahan dan Perubahan Struktur Maya Pencaharian Penduduk. Tahun 1997 dengan 2002 di Daerah Sukoharjo. Jurnal. Universitas Muhammadiyah Surakarta.

Rianse dan Abdi. 2009. Metode Penelitian Sosial Ekonomi. Teori dan Aplikasi Alfabeta. Jakarta.

Rustiadi, E dan R Wafda. 2005. Masalah Ketersediaan Lahan dan Konversi Lahan Pertanian. Makalah yang disampaikan pada Seminar Penanganan Konversi Lahan dan Pencapaian Lahan Pertanian Abadi.

Simatupang, P., dan B. Irawan. 2011. Pengendalian Konversi Lahan Pertanan: Tinjauan Ulang Kebijakan Lahan Pertanian Abadi. Prosiding Seminar Nasional Multifungsi dan Konversi Lahan Pertanian. Penyunting: Undang Kurnia, F. Agus, D. Setyorini, dan A. Setiyanto. ISBN 979-9474-20-5.

Sihaloho, M, A.H. Darmawan dan S. Rusli. 2007. Konversi Lahan Pertanian dan perubahan Struktur Agrarian. Jurnal Transdisiplin Sosiologi, Komunikasi dan Ekologi Manusia. Vol 1. No 2. Tahun 2007.

Yuhri. M., T. 2011. Konversi Lahan Pertanian ke Non Pertanian. Jurnal. Dialektika Edisi 08 Tahun 2011. 